\title{
Operation of Calcium-Birnessite Water-Oxidation Anodes: Interactions of the Catalyst with Phosphate Buffer Anions.
}

\author{
Emanuel Ronge, ${ }^{\mathrm{a}}$ Jonas Ohms, ${ }^{\mathrm{b}}$ Vladimir Roddatis, ${ }^{\mathrm{a}}$ Travis Jones, ${ }^{\mathrm{c}}$ Frederic Sulzmann, ${ }^{\mathrm{c}}$ Axel Knop-

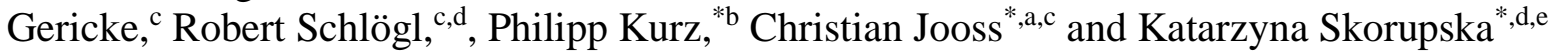 \\ ${ }^{a}$ Institut für Materialphysik, Georg-August-Universität Göttingen, Friedrich-Hund-Platz 1, 37077 Göttingen, Germany. \\ ${ }^{\mathrm{b}}$ Institut für Anorganische und Analytische Chemie and Freiburger Materialforschungszentrum (FMF), \\ Albert-Ludwigs-Universität Freiburg, Albertstraße 21, 79104 Freiburg, Germany. \\ 'International Center for Advanced Energy Studies, Georg-August-Universität Göttingen, Tammannstr. 4, 37077 Göttingen, \\ Germany. \\ ${ }^{\mathrm{d}}$ Max-Planck-Institut für Chemische Energiekonversion, Stiftstraße 34-36, 45470 Mülheim an der Ruhr, Germany. \\ ${ }^{e}$ Fritz-Haber-Institut der Max-Planck-Gesellschaft, Faradayweg 4-6, 14195 Berlin, Germany.
}

KEYWORDS oxygen evolution reaction, manganese oxides, phosphates, ion exchange, electrocatalysis.

\begin{abstract}
Investigating the interfaces between electrolytes and electrocatalysts during electrochemical water oxidation is of tremendous importance for an understanding of the factors influencing catalytic activity and stability. Here, the interaction of a wellestablished, nanocrystalline and mesoporous Ca-birnessite catalyst material (initial composition $\mathrm{K}_{0.2} \mathrm{Ca}_{0.21} \mathrm{MnO}_{2.21} \cdot 1.4 \mathrm{H}_{2} \mathrm{O}$, initial Mn-Oxidation state $\sim+3.8$ ) with an aqueous potassium phosphate buffer electrolyte at $\mathrm{pH} 7$ was studied by using various electron microscopy and spectroscopy techniques. In comparison to electrolyte solutions not containing phosphate, Ca-birnessite electrodes show especially high and stable oxygen evolution activity in phosphate buffer. During electrolysis, partial ion substitutions of $\mathrm{Ca}^{2+}$ by $\mathrm{K}^{+}$and $\mathrm{OH}^{-} / \mathrm{O}^{2-}$ by $\mathrm{H}_{\mathrm{n}} \mathrm{PO}_{4}{ }^{(3-\mathrm{n})-}$ were observed, leading to the formation of a stable, partially disordered $\mathrm{Ca}-\mathrm{K}-\mathrm{Mn}^{-} \mathrm{H}_{\mathrm{n}} \mathrm{PO}_{4}-\mathrm{H}_{2} \mathrm{O}$ layer on the outer and the pore surfaces of the electrocatalyst. In this surface layer, $\mathrm{Mn}$ (III) ions are stabilized, which are often assumed to be of key importance for oxygen evolution catalysis. Furthermore, evidence for the formation of $\left[\mathrm{Ca} / \mathrm{PO}_{4} / \mathrm{H}_{2} \mathrm{O}\right]-\mathrm{complexes}$ located between the $\left[\mathrm{MnO}_{6}\right]$ layers of the birnessite was found using $\mathrm{Ca} 2 \mathrm{p}$ and $\mathrm{Ca}$ L-edge the soft X-ray synchrotron-based spectroscopy. A possible way to interpret the obviously very favorable, "special relationship" between (hydrogen)phosphates and Ca-birnessites in electrocatalytic water oxidation would be that $\mathrm{H}_{\mathrm{n}} \mathrm{PO}_{4}{ }^{(3-\mathrm{n})-}$ anions are incorporated into the catalyst material where they act as stabilizing units for $\mathrm{Mn}^{3+}$ centers and also as "internal bases" for the protons released during the reaction.
\end{abstract}

\section{INTRODUCTION}

One major bottleneck for the production of hydrogen by electrochemical water splitting is the sluggish kinetics of the oxygen evolution reaction (OER). ${ }^{1,2}$ Here, the rational design of better electrocatalysts requires a better understanding of the mechanisms controlling OER activity and stability.

Inspired by the oxygen-evolving complex (OEC) of photosystem II - a $\mathrm{Mn}_{4} \mathrm{CaO}_{5}$ cluster which constitutes the OER active site in biological photosynthesis - a large variety of manganese oxide $\left(\mathrm{MnO}_{\mathrm{x}}\right)$ catalysts has been studied as potential synthetic OER catalyst materials. ${ }^{3-11}$ Beside some crystalline binary or ternary manganese oxides, disordered $\mathrm{MnO}_{\mathrm{x}}$ materials with a low degree of long-range order often show a high intrinsic catalytic activity. ${ }^{11-19}$ For some crystalline systems, the formation of catalytically much more active nanocrystals or disordered surface layers during the OER process has been observed. , $, 6,20-22^{2}$

Among the different less-ordered manganese oxides, birnessites have been identified as especially promising OER catalysts showing both high activity and stability. ${ }^{13,16,23}$ The birnessite structure is built up from edge-sharing $\left[\mathrm{MnO}_{6}\right]$-octahedra forming extended layers. The stacking of the layers in $c$-direction depends on the amount of incorporated water and the type of additional cations and typically results in an interlayer distance of is about $7 \AA .{ }^{13,16,24}$ Many different cations can be present in birnessite-type materials (s-block metal cations are most common) and these lead to different degrees of crystalline order as well as different ion exchange properties in contact with aqueous solutions. ${ }^{25,26}$

Previous studies have shown that the OER activity of birnessites is influenced by various parameter such as their crystallinity, type and concentration of additional cations and synthesis parameters (especially sintering temperatures). For cation incorporation into the birnessite structure, an upper concentration limit is usually observed, which is e.g. $\mathrm{Ca}: \mathrm{Mn} \sim 0.6$ for $\mathrm{Ca}^{2+} .{ }^{27}$

In previous investigations on birnessite-catalyzed OER by some of us, a synthetic birnessite with an approximate composition of $\mathrm{K}_{0.20} \mathrm{Ca}_{0.21} \mathrm{MnO}_{2.21} \cdot 1.4 \mathrm{H}_{2} \mathrm{O}$ emerged as especially active catalyst material in both chemical $\left(\mathrm{Ce}^{4+}\right.$ oxidation) and electrochemical OER screenings. ${ }^{23,27}$ When immobilized onto FTO substrates, stable current densities of $\sim 1 \mathrm{~mA} \cdot \mathrm{cm}^{-2}$ could be reached in neutral, phosphate buffered electrolytes at overpotentials of $\eta \sim 500 \mathrm{mV} .^{28}$ 
Detailed X-ray diffraction and X-ray absorption spectroscopy investigations of this and closely related synthetic Ca-birnessites indicated little long-range, in-plane order and also irregular stackings of the $\left[\mathrm{MnO}_{6}\right]$-layers. ${ }^{13,14,16} \mathrm{~N}_{2}$ sorption experiments revealed a mesoporous structure with quite high surface areas of $\mathrm{S}_{\mathrm{BET}} \sim 50$ $250 \mathrm{~m}^{2} \cdot \mathrm{g}^{-1}$ (mainly depending on the reaction temperatures used during post-synthetic sintering) and average Mn oxidation states were found to be in the range between +3.3 and $+4.0 .{ }^{13,14,16,27}$ The latter observation indicates, that the Mn valence state within the birnessite structure can be reversibly changed - a material property which might be of general, crucial importance for OER catalysis by transition metal oxides. . $^{11,14,29-33}$

Additionally, manganese oxides with oxidation states close to +3.0 exhibit labile Mn-O bonds due to the typical Jahn-Teller distortions of the octahedral coordination spheres of $\mathrm{Mn}^{3+}$ cations ( $h s-$ $\mathrm{d}^{4}$ ), which might promote OER catalysis. ${ }^{3}$ Indeed, oxides rich in $\mathrm{Mn}^{3+}$ often show much higher OER activities than Mn(IV) materials. ${ }^{15}$ On the other hand, the higher charge of $\mathrm{Mn}^{4+}$ seems to inhibit the decomposition of Mn(IV) compounds, as e.g. exemplified by the OEC of photosystem II. ${ }^{33}$

Concerning $\mathrm{MnO}_{\mathrm{x}}$ corrosion in aqueous media, the Pourbaix diagram for $\mathrm{Mn}$ suggests dissolution via solvation of $\mathrm{Mn}^{2+}$ for acidic $\mathrm{pH}$, whereas dissolution of $\mathrm{Mn}$ via the formation of permanganate $\mathrm{MnO}_{4}{ }^{-}$at high anodic potentials is expected for neutral to alkaline $\mathrm{pH} .{ }^{34}$ Both corrosion routes would result in Mn depleted surface layers, and these have indeed been found experimentally. ${ }^{35}$ On the other hand, such corrosion processes might be compensated by repair steps, as e.g. found by Najafpour et al. for reactions of a $\mathrm{K}_{0.25-}$ birnessite with $\mathrm{Ce}^{4+}$. Here, the corrosion products $\mathrm{MnO}_{4}{ }^{-}$and $\mathrm{Mn}^{2+}$ were found to react back to a stable, layered $(\mathrm{K}, \mathrm{Ce}) \mathrm{MnO}_{\mathrm{x}}$ compound, which catalyzed the OER for 15 days without degradation or leaching of manganese. ${ }^{35,36}$ Finally, it has been proposed that redox inert ions like $\mathrm{Ca}^{2+}$ can stabilize $\mathrm{MnO}_{\mathrm{x}}$ and / or facilitate the formation of modified and open structures for water oxidation. ${ }^{35,37}$

Overall the literature data discussed so far hints at a general importance of additional cations for the OER performances of birnessites, not only by influencing the Mn valence state but also by increasing the stability of these $\mathrm{MnO}_{\mathrm{x}}$-based (electro)catalysts. Consequently, the composition of the electrolyte should be carefully chosen in order to control possible cation exchange processes.

In this study, Ca-birnessite coated electrodes were prepared by screen printing the previously mentioned, optimized OER catalyst material $\mathrm{K}_{0.20} \mathrm{Ca}_{0.21} \mathrm{MnO}_{2.21} \cdot 1.4 \mathrm{H}_{2} \mathrm{O}$ on fluorine-doped tin oxide (FTO) as conductive support material following an established and already optimized method. ${ }^{28}$ In order to study the influence of ion exchange reactions on the electrochemical OER activity and stability as well as the material's microstructure, the Ca-birnessite anodes were operated in three different, near neutral aqueous electrolyte solutions: a potassium phosphate buffer $(\mathrm{pH} 7)$, solutions of imidazolium sulphate $(\mathrm{pH} 7.4)$ and potassium sulphate $(\mathrm{pH} 7)$. Structural analyses of the electrodes' surfaces and bulk material were performed using transmission and scanning electron microscopy (TEM/SEM). To gain further insights into the interaction of the electrolyte with the $\mathrm{MnO}_{\mathrm{x}}$ catalyst, we investigated the chemical compositions, Mn valence states and coordination environments by electron energy-loss spectroscopy (EELS) element mapping, energy-dispersive X-ray spectroscopy (EDX), $\mathrm{X}$-ray photoelectron spectroscopy (XPS) and near edge X-ray absorption fine structure (NEXAFS) at the Ca and Mn L-edges. The results hint at a special, favorable interaction between birnessites and phosphate-containing electrolytes, explaining why phosphate buffers might be the medium of choice for birnessite-catalyzed OER at near-neutral $\mathrm{pH}$.

\section{EXPERIMENTAL SECTION}

Please consult previous publications and the supplementary information for details of the synthesis of the Ca-birnessite catalyst material, the preparation of $\mathrm{MnO}_{\mathrm{x}}$-coated electrodes by screen- printing, the exact compositions of the electrolytes as well as the electrochemical measurements. ${ }^{23,28}$

SEM, EDX and cross-section imaging. SEM analysis was carried out with a Nova NanoSem 650 in-situ SEM from FEI. A "through the lens" (TTL) detector was used to take images at an acceleration voltage of $10 \mathrm{kV}$. For energy-dispersive X-ray spectroscopy (EDX), an Oxford Instruments X-Max detector was employed. The quantification of the $\mathrm{Ca} / \mathrm{Mn}$ and $\mathrm{P} / \mathrm{Mn}$ ratios was performed with line-scans of a minimum of 10 points and $100 \mathrm{~s}$ of acquisition time per point over a range of $\sim 60 \mu \mathrm{m}$. The EDX acceleration voltage was $20 \mathrm{kV}$. Cross-section samples used for SEM imaging were cut using a Nova Nanolab 600 focused ion beam (FIB) system from FEI (ion acceleration voltage $30 \mathrm{kV}$ ). For the pristine sample, a protective layer of platinum was first deposited via electron beam induced deposition, followed by a thicker $\mathrm{Pt}$ layer fabricated by ion beam induced deposition. After rough cuts with $3 \mathrm{nA}$ currents, cleaning cuts of the cross sections with $0.3 \mathrm{nA}$ were carried out. The images of the cross sections were taken at an acceleration voltage of $5 \mathrm{kV}$ and an angle of $52^{\circ}$ using the TTL detector.

TEM lamellae preparation and (S)TEM analysis. Electrontransparent cross-section lamellae of $\sim 4 \mu \mathrm{m}$ thick electrodes before and after electrolysis were prepared by means of the FIB system described above. In order to avoid an overlap of the $\mathrm{P}$ and $\mathrm{Pt}$ signals, no protective Pt layer was applied in this case. For the $200 \mathrm{~nm}$ thin electrodes, the lamellas were prepared by conventional cutting, dragging and ion milling using a Gatan Model 691 precision ion polishing system (PIPS). The TEM investigations including imaging, electron energy loss spectroscopy (EELS) and EDXmeasurements were performed using an aberration corrected FEI Titan electron microscope with $300 \mathrm{keV}$ electrons. For this microscope, the information limit in high vacuum is about $0.08 \mathrm{~nm}$. High angle annular dark field (HAADF) imaging was performed in scanning transmission electron microscopy mode (STEM). The STEM capability combined with EELS gives access to the local chemical composition with a spatial resolution of $\sim 0.2 \mathrm{~nm}$ and an energy resolution of $\sim 1.3 \mathrm{eV}$. The following energy edges were used for the EELS-Mapping: Ca - L-edge, Mn - L-edge, O - K-edge, P - Kedge. The TEM EDX analyses were carried out with an Oxford Instruments X-Max detector and electron diffraction patterns were collected with a Phillips CM12 at $120 \mathrm{kV}$.

$\mathrm{X}$-ray spectroscopy. Near-ambient pressure $\mathrm{X}$-ray photoelectron spectroscopy (NAP-XPS) measurements were carried out using a setup located at the Innovative Station for In Situ Spectroscopy (ISISS) beamline at the BESSY II synchrotron of the HelmholtzZentrum Berlin. ${ }^{38}$ For the as-prepared oxide, $\sim 20 \mathrm{mg}$ of Ca-birnessite powder was pressed into a pellet $(\varnothing \sim 2 \mathrm{~mm})$ by applying a force of 1 ton for $1 \mathrm{~min}$. Ca-birnessite-coated FTO slides were directly used for measurements as prepared or after electrochemical operation. In each case, the samples were mounted on a sapphire sample holder and positioned $\sim 1 \mathrm{~mm}$ in front of the first aperture of the differentially pumped electrostatic lens system. Measurements were conducted using an incident X-ray beam spot of roughly $100 \times 300 \mu \mathrm{m}$ at a pressure of $10^{-4}$ mbar. A pass energy of $20 \mathrm{eV}$ was used for XPS measurements and the inelastic mean free path (IMFP) of the photoelectrons was calculated using the model of Tanuma et al.. ${ }^{39}$ The binding energies of measured XPS spectra were calibrated using an $\mathrm{O} 1 \mathrm{~s}$ second order peak with a theoretical photon energy of $730 \mathrm{eV}$. The X-ray photoelectron spectra were recorded at different excitation energies in order to obtain IMFPs of $0.7 \mathrm{~nm}$ (for $\mathrm{E}_{\mathrm{k}}=200 \mathrm{eV}$ ) or $1.7 \mathrm{~nm}\left(\mathrm{E}_{\mathrm{k}}=830 \mathrm{eV}\right)$, respectively. The deconvolution of the XP spectra was performed using the software CasaXPS after subtraction of the Shirley background.

To perform NEXAFS measurements, the photon energy was scanned while the total electron (TEY) and Auger electron (AEY) yields were counted. Ca L-edges spectra were recorded for photon energies between 342 and $362 \mathrm{eV}$, while the photon energy was 
scanned between 625 and $660 \mathrm{eV}$ to cover the $\mathrm{Mn} \mathrm{L}_{3}$ - and $\mathrm{L}_{2}$-edges.

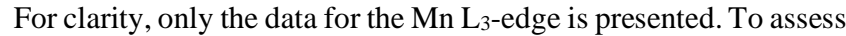
possible beam damage, which is a well-known problem for NEXAFS of manganese oxides, ${ }^{40}$ stability tests were performed. Figure S6 presents three Mn L-edge scans recorded successively on the same spot of three studied samples. The deviations between subsequent scans indicate that Mn ions in the samples are reduced by the beam, but also that the observed spectral changes are small enough so that a meaningful analysis of the spectra is well possible.

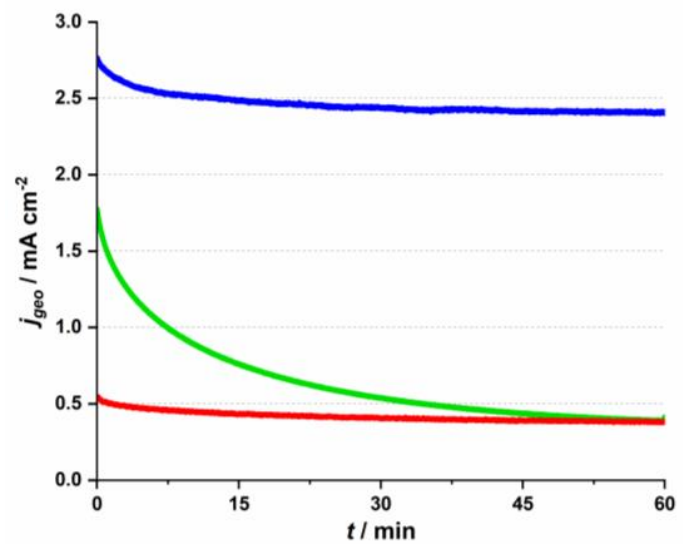

Figure 1. Chronoamperometry of Ca-birnessite / FTO electrodes at $+1.71 \mathrm{~V}$ vs. RHE $(\eta=490 \mathrm{mV})$ in three different, near neutral electrolytes (all $70 \mathrm{mM}$ ): phosphate buffer ( $\mathrm{pH} \mathrm{7,} \mathrm{blue} \mathrm{trace),}$ imidazolium sulfate buffer ( $\mathrm{pH} 7.4$, green trace) and potassium sulfate solution ( $\mathrm{pH} 7$, red trace). $\mathrm{CV}$ can be found in Figure $\mathrm{S} 1$.

\section{RESULTS AND DISCUSSION}

\subsection{Electrochemistry}

The number of possible electrolytes for OER experiments is generally limited as it is of particular importance in OER electrocatalysis that the electrolyte species are themselves redox-inert at strongly oxidizing conditions in water. Among others, the study presented here tries to provide answers to the following two questions concerning OER electrocatalysis by $\mathrm{MnO}_{\mathrm{x}}$ in near-neutral conditions: 1) why is the use of a buffering electrolyte generally beneficial and 2) why are phosphate containing media apparently especially well-suited ${ }^{11}$ Given the general constraint of redox-inertness presented above, we chose the following three electrolytes in order to be able to address these questions experimentally: 1) potassium (di)hydrogen phosphate as a typical phosphate-buffered electrolyte; 2) imidazolium sulfate as a buffering, but phosphatefree medium and 3) potassium sulfate as a solution which is both phosphate-free and not possessing any buffer qualities at $\mathrm{pH}=7$.

In Figure 1, chronoamperometry traces for the three different electrolyte systems are presented. In each case, identically prepared Ca-birnessite/FTO - anodes were immersed in the respective media and an overpotential of $\eta \sim 500 \mathrm{mV}$ was applied for a time of $1 \mathrm{~h}$, while the OER current density was recorded. For details concerning these measurements, please consult ref. ${ }^{27}$.

Interestingly, we find very different $j$ vs. $t$ - traces for the three investigated solutions, despite their virtually identical $\mathrm{pH}$-values and the fact that the applied oxidation potentials were $i R$-compensated to correct for conductivity differences. In all three cases we find that current densities are significantly higher for the first $\sim 2$ min of the experiment, but already here the $j$ observed during the very first phase for phosphate $\left(\sim 2.7 \mathrm{~mA} \cdot \mathrm{cm}^{-2}\right)$ is about $50 \%$ higher than the value for imidazolium $\left(\sim 1.8 \mathrm{~mA} \cdot \mathrm{cm}^{-2}\right)$, while the current for potassium sulfate is very low $\left(\sim 0.2 \mathrm{~mA} \cdot \mathrm{cm}^{-2}\right)$. As already observed in other studies, we again find the current density in phosphate reaches a rather stable value after $\sim 1 \mathrm{~h}$ of operation (here with a current of $\sim 2.5 \mathrm{~mA} \cdot \mathrm{cm}^{-2}$ ). ${ }^{27}$ The higher currents found during the first phase of OER electrocatalysis were previously explained by Mn-centered oxidation events occurring "on top" of the OER current, an explanation e.g. supported by XAS data for the Mn K-edge where a Mn oxidation from an average state of $\sim+3.3$ to $\sim+3.7$ was detected for the Ca-birnessite under electrocatalytic conditions. ${ }^{28}$

For imidazolium, such a steady-state is reached after $\sim 1 \mathrm{~h}$ as well, but here the decrease in current over the first phase is dramatic, leaving a remaining current density of only $\sim 0.5 \mathrm{~mA} \cdot \mathrm{cm}^{-2}$ after $1 \mathrm{~h}$ - and thus less than a third of the starting value. This low current density is the same as observed for the non-buffering potassium sulfate electrolyte during the entire chronoamperometry experiment.

The OER electrocatalysis traces shown in Figure 1 thus clearly demonstrate that 1) a buffering electrolyte solution seems to be generally necessary if significant OER currents are to be reached over significant electrolysis times (phosphate / imidazolium buffers vs. potassium sulfate) and that 2) a phosphate buffer is apparently an exceptionally good choice for OER electrocatalysis by $\mathrm{MnO}_{\mathrm{x}}$ at $\mathrm{pH} 7$, as the also buffering, but phosphate-free imidazolium system both fails to reach the initial current densities found for phosphate by far and also lacks long-term stability.

Next, we were of course eager to identify possible reasons for the profound differences in the electrolysis experiments. For this, we first turned to electron microscopy and X-ray spectroscopy in order to identify differences in morphology and / or elemental composition of the catalytic Ca-birnessite layer after continuous electrocatalysis in the three different solutions.

3.2 Investigations of morphology changes and ion-exchange processes of the catalyst layer by SEM, TEM and EDX

Four different types of samples were investigated by electron microscopy: 1) reference samples of pristine Ca-birnessite electrodes; 2) electrodes after use as water oxidation anodes for different electrolysis times in $70 \mathrm{mM}$ phosphate or 3) $70 \mathrm{mM}$ imidazolium sulfate buffer and 4) samples which had been immersed in a $70 \mathrm{mM}$ phosphate buffer without applying an electrochemical potential. To facilitate the electron microscopy measurements, we prepared Ca-birnessite electrodes with a reduced catalyst layer thickness of $\sim 0.2 \mu \mathrm{m}$ for some of the measurements. 

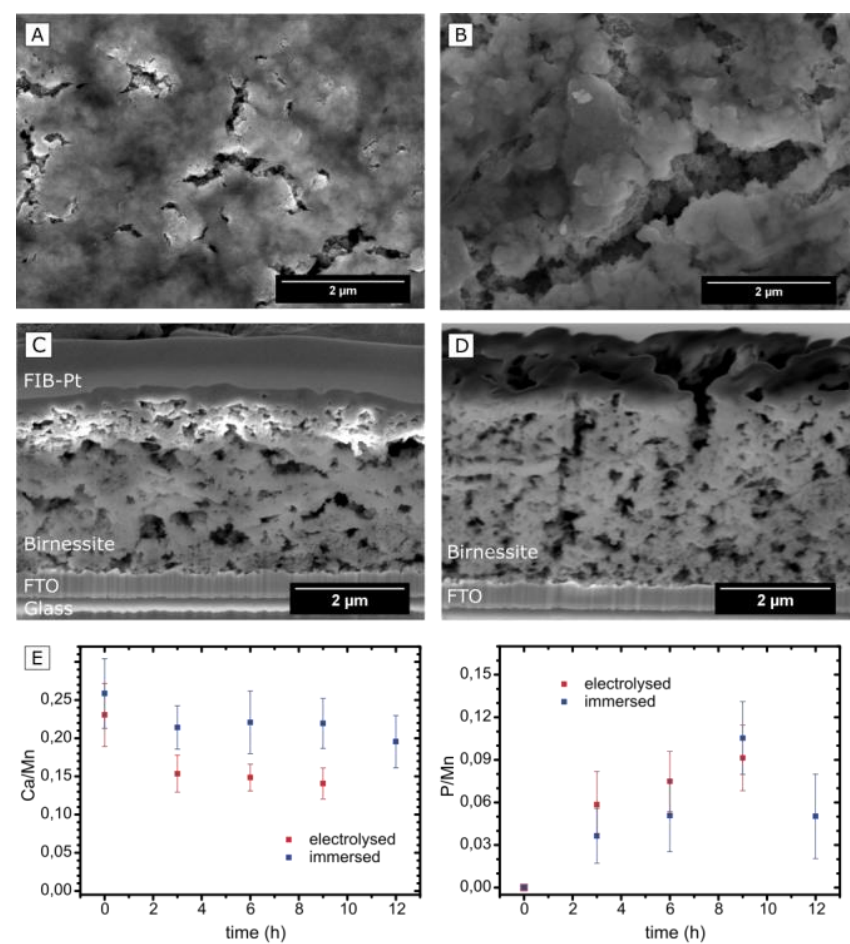

Figure 2. SEM images of Ca-birnessite electrodes. Top views of (A) a pristine electrode; (B) an electrode after $9 \mathrm{~h}$ of electrolysis in $0.07 \mathrm{M}$ phosphate buffer $(\mathrm{pH} 7, \eta=530 \mathrm{mV}$ ); cross-sections of a pristine sample with a protective layer of platinum (C) and a sample after electrolysis (D) without protection layer; (E) EDX-SEM measurements of changes of the $\mathrm{Ca} / \mathrm{Mn}$ and $\mathrm{P} / \mathrm{Mn}$ ratios over time for electrodes subjected to electrolysis in phosphate buffer (red data points) in comparison to samples immersed in phosphate buffer without applying an electrochemical potential (black data points).

The scanning electron microscopy (SEM) images of Figures 2 AD show representative parts of the surface as well as cross-sections of the electrode layer. Clearly visible are agglomerations of particles with a size of a few hundred nanometers forming a rough surface structure. In addition, there are surface cracks which are most likely a result of gaseous $\mathrm{H}_{2} \mathrm{O}$ and $\mathrm{CO}_{2}$ (the latter from carbon-oxidations, see XPS section below) leaving the electrode during the annealing procedure. These observations confirm that the already known mesoporosity and large surface area of the Ca-birnessite powder ${ }^{27}$ are not greatly affected by the fabrication process. The pore morphology is e.g. well illustrated by the SEM cross-sections, where small pores of diameters between 10 and $300 \mathrm{~nm}$ as well as large crack-like openings with a width of several micrometers are visible (Fig. $2 \mathrm{C}$ and $2 \mathrm{D}$ ), supporting a previous characterization of the Ca-birnessite as a mesoporous material with a large surface area. ${ }^{23}$

High-resolution transmission electron microscopy (HRTEM) images show the presence of nanocrystals for both the freshly prepared electrodes and also the electrodes after electrolysis for which a birnessite phase could be assigned by the analysis of the electron diffraction data (see ESI, Figs. S2 and S3).

Post-operando measurements using electron diffraction, XRD and SEM show that neither $9 \mathrm{~h}$ of electrochemical water-oxidation electrolysis nor extended immersion of the electrode into a phosphate-containing electrolyte lead to significant changes of the Cabirnessite layer, therefore confirming previous Raman and XAS results that the birnessite oxide phase and the overall morphology of the catalyst layer is retained during OER. ${ }^{28}$ An important exception to this is the morphology of the electrode surface, where a thin new surface layer is formed during electrolysis which is visible in the TEM images (Fig. 3 and ESI, Fig. S2).
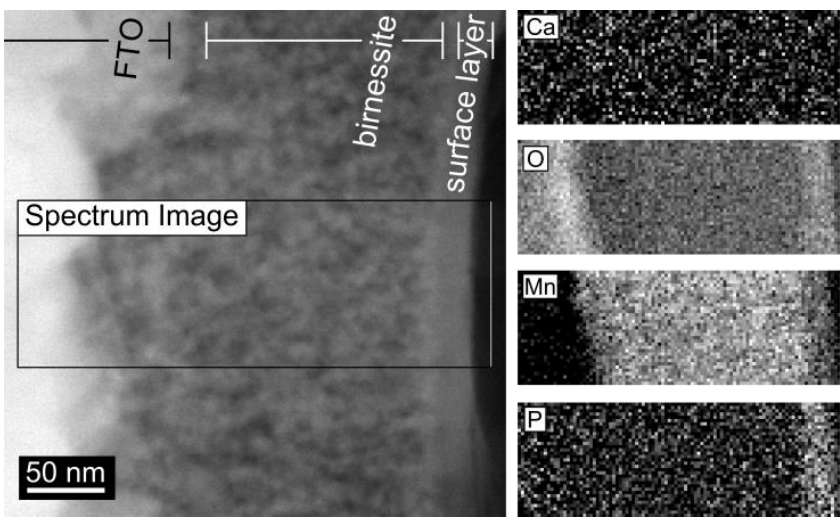

Figure 3. HAADF STEM image (left) and EELS element mapping (right) of a $200 \mathrm{~nm}$ thick birnessite layer used during $12 \mathrm{~h}$ for electrolysis. The FTO substrate is on the far left, the exposed anode surface on the far right part of the images.

Despite the apparently unchanged $\mathrm{MnO}_{\mathrm{x}}$-structure, SEM-EDX indicates that the electrocatalytic process induced significant changes of the average elemental composition for the entire volume of the oxide layer. The calcium concentration decreased markedly, especially during the first $2 \mathrm{~h}$ of electrolysis from an initial $\mathrm{Ca}: \mathrm{Mn}$ ratio of $0.24: 1$ to $\sim 0.14: 1$ (Fig. 2 E). This value seems to represent a new equilibrium concentration as it then remains constant after $\sim 6 \mathrm{~h}$ for the following hours of the electrolysis. In contrast, the $\mathrm{Ca}: \mathrm{Mn}$ ratio of samples which are just immersed in phosphate buffer does not change significantly within the error margin of the detection method. From this we conclude that calcium is not simply dissolved out of the material but rather actively exchanged during the electrocatalytic process.

Given the importance of the electrolyte composition to reach high catalytic current densities (see Fig. 1), a closer look at the distribution of the elements within the material is required. Thus, highangle annular dark field (HAADF) STEM images and EELS mappings of a $200 \mathrm{~nm}$ thick electrode after $12 \mathrm{~h}$ of electrolysis at $\eta=530 \mathrm{mV}$ were recorded (Fig. 3). EELS confirmed the formation of a $\sim 25 \mathrm{~nm}$ thick, phosphorous-rich surface layer (far right part of the images in Fig. 3). This surface layer also contains manganese, oxygen and (very little) calcium. Based on the EELS mapping, we however cannot make a statement about the presence of phosphorous in the entire volume of the catalyst layer, because the phosphorous K edge at $2146 \mathrm{eV}$ is too weak to detect phosphorous concentrations below $\sim 5$ atom $\%$. On the other hand, we were able to detect $\mathrm{P}$ in the entire birnessite-layer using TEM-EDX, as EDX is much more sensitive for $\mathrm{P}$ but unfortunately does not offer space resolution. For a sample with a thickness of $\sim 4 \mu \mathrm{m}$ that had been operated as OER anode for $9 \mathrm{~h}$, the average $\mathrm{P}$ : Mn ratio for bulk birnessite was determined by TEM-EDX as $\sim 0.15: 1$ (Fig. 4) and thus as very similar to the ratio reported above as the final state of the exchange equilibrium after $9 \mathrm{~h}$ of operation(Fig. $2 \mathrm{E}$ ). However, despite of the good agreement of the average values, the fluctuations of the local $\mathrm{P}: \mathrm{Mn}$ ratios are in the order of $\sim 65 \%$. As can be seen in Figure $4 \mathrm{~A}$, there is a correlation between the phosphorous signal in the EDX map and the contrast of the STEM-image (which is a measure of the local lamella thickness). 

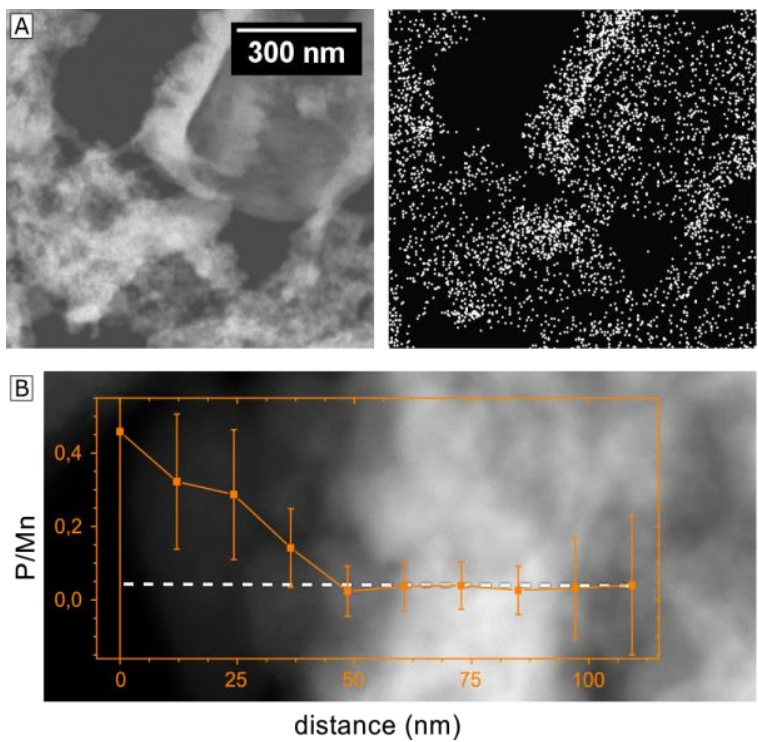

Figure 4. (A) EDX element mapping for a $\sim 4 \mu \mathrm{m}$ thick birnessite electrode after $9 \mathrm{~h}$ of electrolysis $(\eta=530 \mathrm{mV})$. left: HAADF STEM image of the mesoporous oxide structure; right: EDX map of phosphorus for the same part of the oxide layer (EDX sum-spectra in Fig. S4 A). The color levels of the phosphorus map were adjusted for better visibility; (B) EDX line scan from a pore surface into a nano-crystalline dense area of the same lamella as shown in B. Foreground: EDX line scan of the $\mathrm{P}: \mathrm{Mn}$ ratio; Background: (HAADF) STEM image of the area of the line scan. The dashed line shows the location of the scan.

Altogether, the element mapping data offers strong evidence for the presence of phosphorous in the entire birnessite volume. The detected variations of the phosphorous concentration can partially be explained by variations of the sample thickness, but also reflect real fluctuations within the nanocrystalline material. A further explanation can be found by a closer look at Figure 4 B. Here, an EDX line scan over a distance of only $100 \mathrm{~nm}$ indicates a much higher $\mathrm{P}: \mathrm{Mn}$ ratio close to the surface of an inner pore of the birnessite film in comparison to the denser bulk of the material. This observation might also represent an early stage of the formation of a phosphorous-rich surface layer similar to the feature at the outer electrode surface shown in Figure 3. Additional EDX line scans at high spatial resolution were recorded and these are also in agreement with the general conclusion that phosphorous is mainly located on the surfaces of the birnessite nanocrystals (see ESI, Fig. S5).

In order to investigate whether the anion-exchange-processes during electrolysis are unique for the P / Mn couple, we compared the observations for the phosphate buffer to the buffering, but phosphate free imidazolium electrolyte. Here, the ion exchange processes were analyzed by transmission electron microscopy for $200 \mathrm{~nm}$ thick Ca-birnessite layers after $12 \mathrm{~h}$ of electrolysis. In Figures $5 \mathrm{~A}, \mathrm{C}$ and $\mathrm{E}, \mathrm{EDX}$ line scans of the electrode after an electrolysis in the phosphate buffer are shown. Similar to Figure 4, a significantly higher $\mathrm{P}: \mathrm{Mn}$ ratio can be observed. Despite the overlap off the Pt and P peaks in den EDX spectra, the data indicates a significant $P$ concentration in the subsurface region down to $10 \mathrm{~nm}$. In contrast, Figures $5 \mathrm{~B}, \mathrm{D}$ and $\mathrm{F}$ show the same dataset for a sample after electrolysis in the imidazolium sulfate electrolyte. Interestingly, here the sulfur signals (which would indicate sulfate binding) are barely above the noise level. We conclude that, unlike for phosphate, no sulfate containing surface layer is apparently formed during OER electrocatalysis in the imidazolium sulfate electrolyte. This interpretation is also supported by SEM-EDX measurements for a $4 \mu \mathrm{m}$ thick sample after $9 \mathrm{~h}$ of electrolysis in imidazolium sulfate, where no sulfur signal was detected (see ESI, Fig. S4 B). For the $\mathrm{Ca} / \mathrm{Mn}$ ratio, a value of $0.11 \pm 0.06$ could be calculated from the SEM-EDX data, indicating partial removal of calcium from the material to a very similar degree as found before for phosphate.
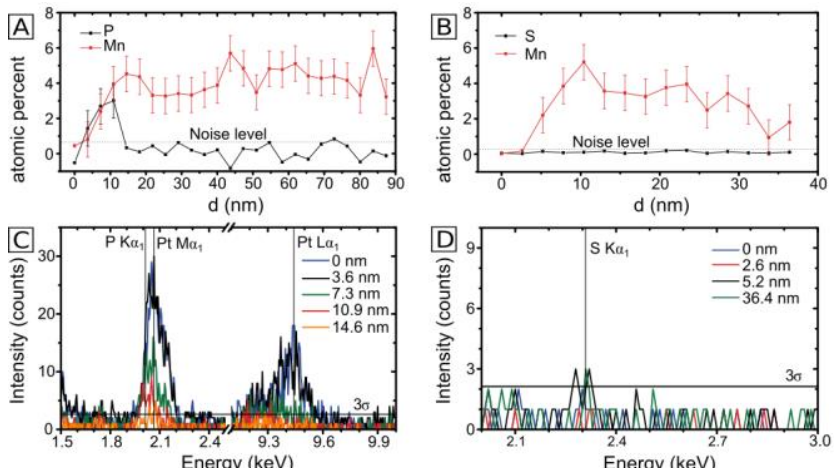

E

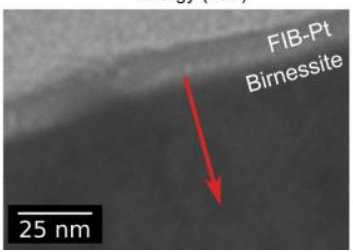

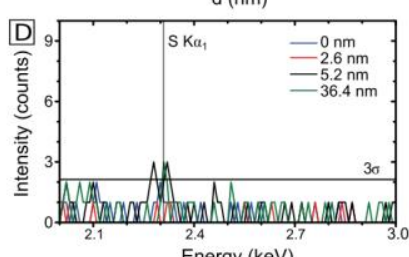

F

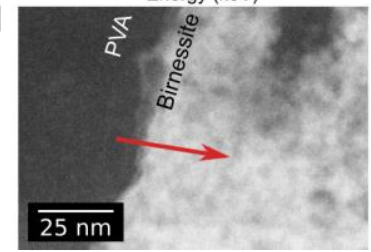

Figure 5. Comparison of $200 \mathrm{~nm}$ thick birnessite electrodes after $12 \mathrm{~h}$ of electrolysis in $70 \mathrm{mM}$ phosphate buffer (left column) and imidazolium sulfate (right column). (A-B): EDX line scans taken at cross sections of the electrode surface, where the surface position is set to $0 \mathrm{~nm}$, the dotted line indicates the noise level of the EDX measurement; (C-D): corresponding EDX spectra taken at different positions, the horizontal line represents the $3 \sigma$ level of the noise; (E-F): HAADF image of the position of the line scans.

In summary, the presented electron microscopy results confirm that the mesoporous calcium-manganese oxide used here as electrocatalyst retains its nanocrystalline, birnessite-like structure during the electrolysis process, even as at least one third of the initially present $\mathrm{Ca}^{2+}$ ions are lost and / or replaced during electrocatalysis. For the phosphate buffered electrolyte, $\mathrm{P}$ enters the entire volume of the birnessite material. In addition, a P-rich oxide layer with a thickness of 15 - $20 \mathrm{~nm}$ forms at the outer surface of the electrode. After extended electrolysis, phosphorous can finally be found all over the sample, but its distribution appears to be inhomogeneous as the inner surfaces of the pores and the surfaces of the nanocrystals show much higher P-concentrations than the dense, nanocrystalline parts of the Ca-birnessite. The observed high and stable catalytic activity might thus be correlated to the formation of a P-containing, calcium-manganese oxide surface layer acting as "true" OER electrocatalyst.

3.3 Ca-Birnessite / electrolyte interactions probed by XPS and NEXAFS.

The results from the previous sections indicate that different ion exchange processes take place when the Ca-birnessite material is used as OER electrocatalyst in phosphate buffer: $\mathrm{Ca}$ ions are partially exchanged and phosphate ions enter the material. In contrast, no sulfur incorporation was detectable after electrolysis in imidazolium sulfate. These different ion interactions, the accompanying changes of the Mn oxidation states and the role of calcium were now studied in more detail using X-ray spectroscopy methods.

X-ray photoelectron spectroscopy (XPS) and near edge X-ray absorption fine structure spectroscopy (NEXAFS) were performed with the aim to gain insights into both the elemental composition and the chemical bonding situation. Such measurements typically probe the material close to the electrode surface (the penetration 
depth of a few nanometers) and thus have to be seen as complimentary e.g. to the previously carried out XAS measurements at the Mn K-edge, ${ }^{30}$ as well as the EDX and SEM experiments described above, all of which provide information about the entire $\mu \mathrm{m}$-thick oxide layer. Similar to the previous section, XPS and NEXAFS spectra were recorded for four different types of samples: 1) the synthetic Ca-birnessite powder, 2) pristine Ca-birnessite electrodes, 3 ) electrodes after $16 \mathrm{~h}$ of operation at $+1.77 \mathrm{~V}$ vs. RHE $(\eta=540 \mathrm{mV})$ in $70 \mathrm{mM}$ phosphate buffer and for comparison 4$)$ in $70 \mathrm{mM}$ imidazolium sulfate buffer.

XPS survey spectra for samples 1 to 3 between 0 and $1200 \mathrm{eV}$ are shown in Figure 6. As expected for a calcium containing manganese oxide, the most intense signals in all spectra are observed for the $\mathrm{O} 1 \mathrm{~s}$ and the Mn 2p electrons and calcium lines can also be found in all cases. The presence of weak tin signals from the underlying FTO substrate confirms the already detected cracks and/or the porosity of the catalyst layers, which allows some photons to reach the underlying $\mathrm{SnO}_{2}: \mathrm{F}$ support material. In addition, freshly prepared electrodes contain a significant amount of carbon, which must originate from the binder substances used during the printing process as carbon is not visible in the spectrum of the synthetic oxide on its own.

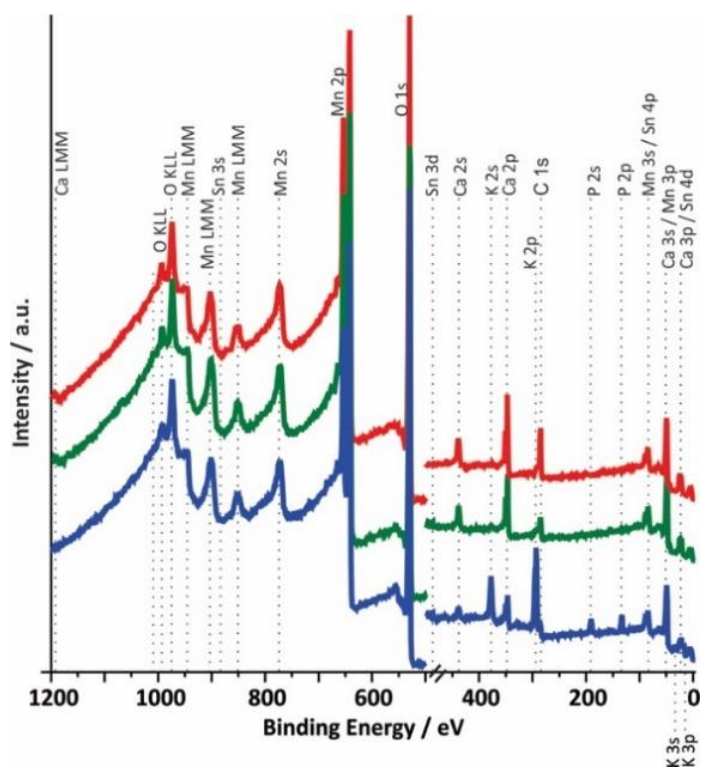

Figure 6. X-ray photoelectron survey spectra (XPS, $\mathrm{h} \cdot v=1486.7 \mathrm{eV})$ of different Ca-birnessite samples. red: synthetic Ca-birnessite powder, green: screen printed, $10 \mu \mathrm{m}$ thick Ca-birnessite layer on FTO substrate after annealing at $450{ }^{\circ} \mathrm{C}$ and blue: XPS of an electrode after $16 \mathrm{~h}$ of OER electrocatalysis in $0.1 \mathrm{M}$ phosphate buffer $(\eta=540 \mathrm{mV})$.

The most obvious differences between the spectra recorded for Ca-birnessite electrodes before and after $16 \mathrm{~h}$ of OER electrocatalysis in phosphate buffer are the appearances of additional signals for potassium and phosphorous in the spectral region between 100 and $400 \mathrm{eV}$ (Fig. 6, blue trace), which coincide with a marked decrease of the Ca peak intensity. On the other hand, the fact that the XPS spectra of Figure 6 are overall very similar again confirms that the electrocatalyst layer retains the characteristics of a layered calcium manganese oxide even after extended electrolysis time. However - and in full agreement with the results from the previous section - we also observe significant changes of the chemical composition caused by the electrocatalytic process (this time for the zone close to the surface accessible to XPS): most of the carbon and some calcium leave the $\mathrm{MnO}_{\mathrm{x}}$-layer, while potassium and phosphate from the electrolyte enter the material. In case of the imidazolium sulfate electrolyte, no S 1 s line was found and additionally the Ca signals in the survey spectrum are not detectable any more after electrochemistry (see ESI, Fig. S7). Thus XPS confirms that very different ion exchange processes are at play when these two buffer systems interact with the Ca-birnessite catalyst during OER.

In order to obtain more detailed information about the chemical environment of the different elements, we also analyzed the Mn and $\mathrm{Ca}$ L-edge spectra in combination with the XPS data for Mn 2p, $\mathrm{O} 1 \mathrm{~s}, \mathrm{P} 2 \mathrm{p}$ and $\mathrm{Ca} 2 \mathrm{p} .{ }^{28,41-44}$ The spectra were measured at kinetic electron energies of $200 \mathrm{eV}$ or $830 \mathrm{eV}$ which relate to inelastic mean free paths (IMFP) for the electrons of $\sim 1$ or $\sim 2 \mathrm{~nm}$, respectively. The NEXAFS spectra were taken both in the detection modes total electron yield (TEY, probing depth $3-10 \mathrm{~nm}$ ) as well as Auger electron yield (AEY, probing depth $<1 \mathrm{~nm}$ ). The same spectral features were found in both modes and thus only the TEY spectra are shown in Figures 7 and 8 (see also ESI, Fig. S6).

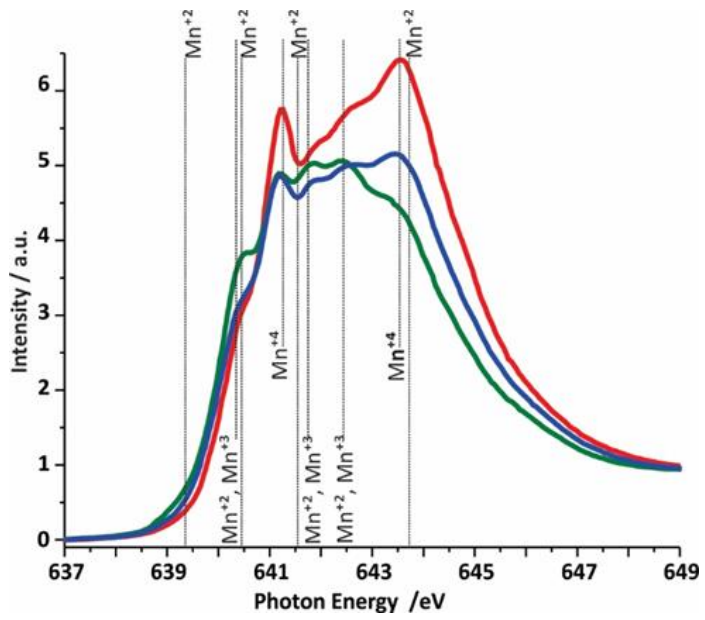

Figure 7. $\mathrm{Mn} \mathrm{L}_{3}$-edge NEXAFS (TEY) spectra of the three different Ca-birnessite samples studied by XAS. Color code and sample descriptions are identical to Figure 6.

The O 1s XP spectra show contributions from water, Mn-bound hydroxide and bridging $\mu$-oxido ligands between two Mn centers (see ESI, Fig S8). A comparison of the data for the different electron energies indicates (as expected) a higher concentration of hydroxide groups and water at the surface of the samples compared to the underlying oxide volume. Furthermore, the spectral differences between the three samples show that the hydroxide concentration of the precursor powder is higher than that of the annealed electrode, but smaller than in the used electrodes. This is also expected, as the calcination step at $450^{\circ} \mathrm{C}$ used for the electrode preparation should result in the elimination of $\mathrm{OH}^{-}$and/or $\mathrm{H}_{2} \mathrm{O}$ from the material, while the exposure to the aqueous medium during electrolysis will result in a renewed binding of these species. The shoulder appearing at $530.8 \mathrm{eV}$ for the sample after electrochemistry can be connected to phosphates originating from the electrolyte. ${ }^{45,46} \mathrm{As}$ can be seen in Figure S8, the surface of the electrode $\left(\mathrm{E}_{\mathrm{B}}=200 \mathrm{eV}\right)$ shows a more pronounced signal related to the phosphate electrolyte residuals.

To gain insights into the oxidation states of the manganese species located on the surface of the electrode, NEXAFS spectra were taken at the $\mathrm{Mn} \mathrm{L}$-edges and the recorded $\mathrm{Mn} \mathrm{L}_{3}$-edge spectra are shown in Figure 7. The Mn $2 p$ spectra for all the samples were also measured (ESI, Fig. S15). Due to significant multiplet splitting of the three oxidation states of manganese (II, III, IV), and the overlapping binding energy for these multiplet splitting structures we 
decided to focus on the Mn L-edge (NEXAFS) analysis. From comparisons of reference data ${ }^{47}$ with the spectra measured for reference oxides and used for the difference spectra analysis (Fig. S9) and also for linear combination analysis (LCA) (Fig. S9a), we conclude that the as-prepared Ca-birnessite powder mainly contains $\mathrm{Mn}$ in the form of $\mathrm{Mn}^{4+}$ ions, giving rise to two pronounced NEXAFS peaks at 641.3 and $643.5 \mathrm{eV}$, respectively (59\% $\mathrm{Mn}^{4+}$ vs. $41 \%$ $\mathrm{Mn}^{3+}$ from LCA). During electrode preparation, manganese is partially reduced (most likely by the organic components of the ink, see XPS results for carbon) to an oxide material containing Mn predominantly in its $\mathrm{Mn}^{3+}$ oxidation state (LCA here: $7 \% \mathrm{Mn}^{2+}, 6 \%$ $\mathrm{Mn}^{2+} / \mathrm{Mn}^{3+}, 65 \% \mathrm{Mn}^{3+}$ and $22 \% \mathrm{Mn}^{4+}$ ). This is manifested by two additional NEXAFS signals at 641.8 and $642.4 \mathrm{eV}$, while the feature at $643.5 \mathrm{eV}$ almost disappears from the spectrum. Electrolysis at OER conditions results in a re-oxidation of manganese and the $\mathrm{Mn}^{4+}$-peak at $643.5 \mathrm{eV}$ reappears. However, the peaks assigned to $\mathrm{Mn}^{4+}$ do not reach the same intensities after electrolysis as initially found for the powder sample, which suggests that a certain concentration of $\mathrm{Mn}^{3+}$ is still present on the material surface even after extended electrolysis at OER potentials (LCA after electrolysis: $2 \%$ $\mathrm{Mn}^{2+}, 5 \% \mathrm{Mn}^{2+} / \mathrm{Mn}^{3+}, 45 \% \mathrm{Mn}^{3+}$ and $48 \% \mathrm{Mn}^{4+}$ ). This observation differs from the behavior of birnessites containing only potassium as additional cation ${ }^{48,49}$ and it is thus feasible that the $\mathrm{Ca}^{2+}$ ions have a stabilizing effect on the $\mathrm{Mn}^{2+}$ and $\mathrm{Mn}^{3+}$ oxidation states.

When an oxidizing potential was applied to the electrode in buffered electrolyte solutions, we detected electrochemical "prewaves" in the CVs (see ESI, Fig. S1) and also some reorganization of the material at its surface by electron microscopy. Both processes most likely involve complex Mn-centered redox reactions. ${ }^{28}$ In the light of the changes observed in the Mn NEXAFS spectra, we can now identify electrochemical oxidations of $\mathrm{Mn}^{3+}$ and possibly also $\mathrm{Mn}^{2+}$, (see Fig. S6 in the ESI) centers to $\mathrm{Mn}^{4+}$ occurring for $\mathrm{E}>1 \mathrm{~V}$ to be responsible for these events.

Next, the XPS and NEXAFS data for calcium was analyzed (Fig. 8 and ESI, Fig. S10). The Ca 2p spectra were measured at kinetic energies of $E_{k}=200 \mathrm{eV}$ and $\mathrm{E}_{\mathrm{k}}=830 \mathrm{eV}$, respectively. A quantitative analysis of the $\mathrm{Ca} 2 \mathrm{p}$ spectra shows that the calcium ions are eliminated from the structure resulting in a decrease of the $\mathrm{Ca}: \mathrm{Mn}$ ratio from $0.3: 1$ for the powder sample and $0.18: 1$ for the freshly prepared electrode to $0.11: 1$ for the electrode after electrochemical performance in phosphate buffer. These numbers are in very good agreement with EDX-SEM measurements described above.

Deconvolutions of the $\mathrm{Ca} 2 \mathrm{p}$ lines yielded a main doublet at $346.4 \mathrm{eV}$ for all samples (Fig. 8). From the literature, this is typical for calcium manganese oxides like $\mathrm{CaMnO}_{3}$ or $\mathrm{CaMn}_{2} \mathrm{O}_{4}$, where $\mathrm{Ca}^{2+}$ interacts with neighboring $\mathrm{Mn}^{3+/ 4+}$ cations via $\mu$-oxido bridges.$^{50}$ After electrolysis in phosphate buffer, both the $\mathrm{Ca} 2 \mathrm{p}$ (XPS) and the Ca L-edges (NEXAFS) spectra show additional contributions when compared to those of the powder sample or the pristine electrode, indicating that some of the $\mathrm{Ca}^{2+}$ ions enter a new chemical environment during electrochemical OER in phosphate buffer. In the XPS, after electrolysis an additional peak is found in the $\mathrm{Ca} 2 \mathrm{p}$ spectrum at a higher binding energy of $353.5 \mathrm{eV}$. Furthermore, NEXAFS shows an additional resonance at a lower excitation energy. This effect was observed only when phosphate buffer was used as electrolyte, while in the case of imidazolium sulfate no additional Ca L-edge feature was observed (see ESI, Fig. S11)

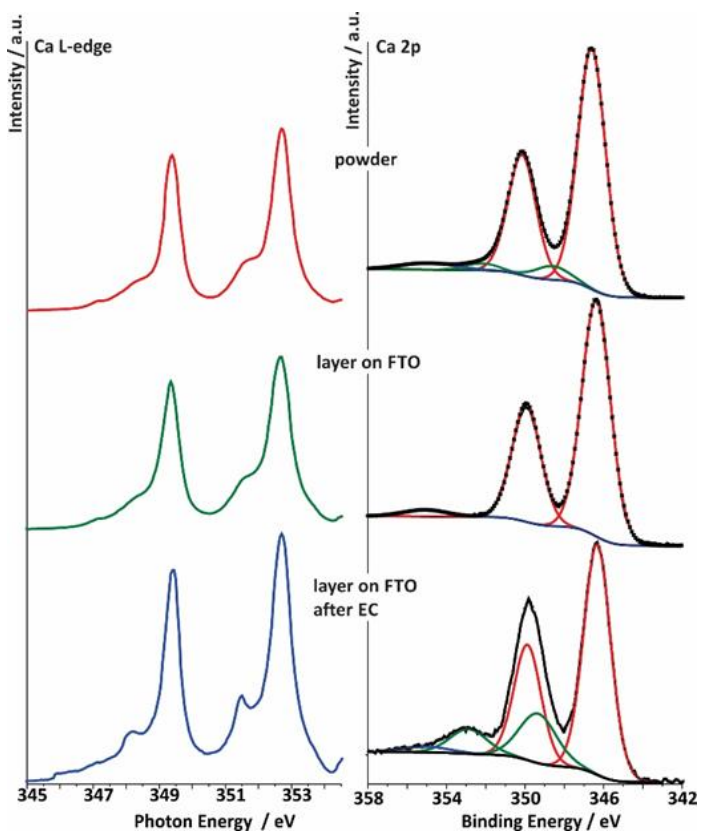

Figure 8. right: deconvoluted Ca $2 p$ spectra (data for $E_{k}=830 \mathrm{eV}$ ) of the three different Ca-birnessite samples studied by XAS: powder (top), printed Ca-birnessite layer on FTO before (middle) and after electrolysis in phosphate buffer (bottom). left: Ca L-edge NEXAFS spectra of Ca-birnessite samples in total electron yield (TEY) mode. Color code and sample descriptions are identical to Figures 8 and 9.

The calcium ions in the interlayer space of birnessite-type oxides are expected to show strong Coulomb interactions with the oxido anions of the $\left[\mathrm{MnO}_{6}\right]$ layers and neighboring water molecules. On the other hand, we found that most of the $\mathrm{Ca}^{2+}$ is removed from the birnessite material during OER in imidazolium sulfate (see ESI, Fig. S7). In this case, the $\mathrm{Mn} \mathrm{L}_{3}$-edge spectrum is also dominated by $\mathrm{Mn}^{4+}$ (Fig. S12) and an analysis of the data shows that there is ca. $20 \%$ less $\mathrm{Mn}^{3+}$ present in comparison to the sample obtained after electrolysis in phosphate buffer (LCA here: $6 \% \mathrm{Mn}^{2+}, 7 \%$ $\mathrm{Mn}^{2+} / \mathrm{Mn}^{3+}, 21 \% \mathrm{Mn}^{3+}$ and $66 \% \mathrm{Mn}^{4+}$; see ESI, Fig. S9a). To us, it seems that all these observations might be explainable by the following interwoven effects: 1) $\mathrm{Ca}^{2+}$ - phosphate interactions obviously stabilize $\mathrm{Ca}^{2+}$ within the birnessite, 2) it is known that secondary cations like $\mathrm{Ca}^{2+}$ influence the energetics of the conversion of $\mathrm{Mn}^{4+}$ to $\mathrm{Mn}^{3+},{ }^{51}$ so that in consequence 3 ) the presence of phosphate, mediated via the $\mathrm{Ca}^{2+}$ ions in the material, stabilize lower oxidation states of manganese in the Ca-birnessite catalyst and thus make it more active in OER catalysis.

To test this assertion, we noticed that all XP spectra of Figure 8 feature a Ca $2 \mathrm{p}$ satellite peak at about $355 \mathrm{eV}$. At $\sim 10 \mathrm{eV}$ of energy above the main line, these signals could well be exciton satellites associated with $\mathrm{Ca}^{2+} .{ }^{52,53}$ However, the spectra for the Ca-birnessite powder and post-operando spectrum from the phosphate electrolyte additionally contain a satellite just $3 \mathrm{eV}$ above the main line. It is accepted that such additional high energy features in XPS are charge transfer satellites resulting from the hybridization between valence orbitals of cations and anions, in our case $\mathrm{Ca}^{2+}$ and $\mathrm{O}^{2-}$ (for more details see ESI, $4^{\text {th }}$ text paragraph and Fig. S13b). ${ }^{52-54}$

This hybridization can effectively be described by charge transfer from the ligand to the metal, resulting in a $\mathrm{d}^{1} \underline{\mathrm{L}}$ configuration, where $\underline{L}$ denotes a ligand hole and $\mathrm{d}^{1}$ indicates an additional d electron on the metal. The energy separation between these satellites and the main $\mathrm{Ca} 2 \mathrm{p}$ line is indicative of the degree of hybridization. For the powder birnessite sample, the energy separation between the primary peak and the charge transfer satellite is $2 \mathrm{eV}$ (Fig. 8, right). 
After electrochemistry the separation between the satellite and the main line increases to $2.7 \mathrm{eV}$, which indicates that the $\mathrm{d}^{1} \underline{\mathrm{L}}$ final state has a lower energy than in the powder, meaning that the $\mathrm{Ca}^{2+}$ remaining after electrochemistry is bound through a highly covalent metal-ligand interaction.

Turning now to the oxide material obtained after printing onto the FTO substrate, we see that the charge transfer satellite seen initially in the powder sample is lost (Fig. 8). Unlike the partially covalent ground state found after electrochemistry, the ground state after printing on FTO is then dominated by the ionic $\mathrm{d}^{0}$ configuration. The origin of this change in covalency can be seen on the basis of hybrid density functional theory calculations which show an increase in both band gap and $\mathrm{Ca}-\mathrm{O}$ distance in the presence of a high concentration of $\mathrm{Mn}^{3+}$ ions due to the Jahn-Teller distortion of these centres. ${ }^{55}$ Thus, the appearance of a high concentration of $\mathrm{Mn}^{3+}$ may lead to a loss of the charge transfer satellite in the Ca 2p XPS and a decrease in covalency of the Ca oxygen bonds. To test if this is the case, we turned to the Mn Ledge measurements (Figure 7), from these spectra it seems that the existence of the $\mathrm{Ca} 2 \mathrm{p}$ charge transfer satellite may be connected with the presence of $\mathrm{Mn}^{4+}$. After printing, the sample is composed primarily of $\mathrm{Mn}^{3+}$ and there is no charge transfer satellite in the $\mathrm{Ca}$ $2 p$ XP spectrum. However, when $\mathrm{Mn}^{4+}$ dominates the $\mathrm{Mn} \mathrm{L}$-edge spectra as in the powder sample and the sample after electrochemistry, the charge transfer satellite is seen in the Ca $2 \mathrm{p} \mathrm{XP} \mathrm{spectrum.}$ In the latter case, a slightly more covalent character of the metal ligand interaction was found and the Mn L-edge spectrum also shows a contribution of $\mathrm{Mn}^{3+}$.

The analysis of the Ca L-edge spectra shows that the spectrum recorded for the electrode after OER electrocatalysis in phosphate buffer shows an additional feature similar to what was found for the XPS Ca $2 p$ lines. The main spin-orbit related peaks L3 (2p $\left.\mathrm{p}_{3 / 2}\right)$ and $\mathrm{L} 2\left(2 \mathrm{p}_{1 / 2}\right)$ at $349.4 \mathrm{eV}$ and $252.7 \mathrm{eV}$, respectively, are present in all three spectra. The position of these main absorptions is nearly the same for all three samples. For the sample treated electrochemically in phosphate buffer, peaks appear at $348.2 \mathrm{eV}$ and $351.47 \mathrm{eV}$, while spectra of the two others samples show only small shoulders at these photon energies.

The $\mathrm{Ca}$ L-edge spectra is known to be dominated by transitions into localized $\mathrm{Ca} 3 \mathrm{~d}$ states meaning that $\mathrm{p} \rightarrow \mathrm{s}$ transitions can be ignored to first approximation. ${ }^{56}$ Thus, for $\mathrm{Ca}^{2+}$ without hybridization, the final state in NEXAFS is $\left|c d^{1}\right\rangle$. In spherical symmetry this would lead to two primary lines associated with the $\mathrm{p}_{3 / 2}$ and $\mathrm{p}_{1 / 2}$ initial states, while in an octahedral field the d orbitals are no longer degenerate and two final states become available for each initial state. If we furthermore include the hybridization approach we used to explain the Ca $2 \mathrm{p}$ XP spectra, additional NEXAFS features can appear due to the increase in multiplet lines. ${ }^{57}$

It is difficult to know a priori how these additional states modify the Ca L-edge spectrum. Thus, we calculated the spectra using a multiplet Hamiltonian that includes hybridization with the same parameters as for the XPS calculations described above. These calculations reproduce the L-edge spectrum expected for both the $\mathrm{Ca}^{2+}$ ion of spherical symmetry and $\mathrm{Ca}^{2+}$ in an octahedral environment of $\mathrm{O}^{2-}$ counter-ions $\left(10 \mathrm{D}_{\mathrm{q}}=0.75 \mathrm{eV}\right)$ (see ESI, Fig. S13a). They also reveal additional small leading edge peaks due to multipole interactions of the core hole with the valence electron. ${ }^{57} \mathrm{~A}$ comparison of these calculated L-edge spectra with the experimental results shows that $\mathrm{Ca}^{2+}$ interacts weakly with its surroundings in the as prepared birnessite powder, with a value of only $10 \mathrm{D}_{\mathrm{q}}=0.75 \mathrm{eV}$ required to model the shoulders at $348.2 \mathrm{eV}$ and $351.5 \mathrm{eV}$. For comparison, $10 \mathrm{D}_{\mathrm{q}}$ is $1.2 \mathrm{eV}$ in $\mathrm{CaO} .{ }^{57}$ When hybridization is introduced, it leads to the growth of two peaks, consistent with what is observed in the measured Ca L-edge spectrum after electrochemistry in phosphate buffer (see Fig. 8, left, blue curve).

The agreement between the theoretical description of the NEXAFS and XPS spectra allows us to conclude that the additional peaks in the Ca L-edge spectra recorded for the electrode sample after OER electrocatalysis in phosphate buffer can be assigned to a partial change in environment of the calcium ions. This indicates the formation of a new $\mathrm{Ca}^{2+}$-containing phase, in which the Ca-ligand interaction becomes highly covalent, and therefore resistant to dissolution into the electrolyte. For the sample obtained from the imidazolium sulfate electrolyte, such additional features at $348.2 \mathrm{eV}$ and $351.47 \mathrm{eV}$ are not observed, suggesting that hybridization between $\mathrm{Ca}^{2+}$ and $\mathrm{O}^{2-}$ is not taking place in this case and might thus be phosphate-dependent (see ESI, Fig. S11).

The survey XP spectrum of the sample after electrochemistry in phosphate buffer also revealed the presence of a $\mathrm{P} 2 \mathrm{p}$ signal, which must originate from phosphate ions incorporated into the oxide (Fig. 6). At this stage it is unclear whether this signal might also originate from calcium phosphates $\left(\mathrm{E}_{b}=347-348 \mathrm{eV}\right)$ as possible products from the reaction between $\mathrm{Ca}^{2+}$ from the Ca-birnessite and ( $\mathrm{H}) \mathrm{PO}_{4}{ }^{2 / 3-}$ anions from the electrolyte. ${ }^{58}$ Taking into account the well-studied chemistry of calcium phosphates and the TEM-EDX data presented above (where phosphorous was found close to the surfaces of the Ca-birnessite nanocrystals), the formation of some kind of calcium phosphate moieties seems plausible. Unfortunately, in our case calcium phosphate species cannot be identified by their Ca $2 p$ XP spectra as the binding energies for calcium manganese oxides and calcium phosphates are separated by less than $1 \mathrm{eV} .^{51}$

Nevertheless, in order to be able to detect possible contribution from calcium phosphates next to calcium manganese oxides, a P 2p XPS for the electrode after electrolysis was measured using two kinetic energies $\left(E_{k}=200 \mathrm{eV}\right.$ and $830 \mathrm{eV}$, see ESI, Fig. S14). The two spectra differ by a greater bulk contribution $\left(\mathrm{E}_{\mathrm{k}}=820 \mathrm{eV}\right.$ vs. $\mathrm{E}_{\mathrm{k}}=200 \mathrm{eV}$ ) of a phase appearing at higher binding energy $(\sim 136 \mathrm{eV})$. After deconvolution of the $830 \mathrm{eV}$ spectrum, three doublets were found (Fig. 9). A comparison with literature data combined with theoretical calculations allows an analysis of the contributions to this $\mathrm{P} 2 \mathrm{p}$ peak: the first doublet located at $132.8 \mathrm{eV}$ (red line) can be assigned to $\mathrm{HPO}_{4}{ }^{2-}$ and $\mathrm{H}_{2} \mathrm{PO}_{4}^{-}$, the buffer anions present in the electrolyte. ${ }^{58}$ The second (133.7 eV) (blue line) and third $(135.75 \mathrm{eV})$ (green line) doublet are related to each other. The energetic position of the second doublet is in very good agreement with the literature data for calcium phosphates and the formation of such compounds from the reaction between phosphate from the electrolyte and calcium ions located within the birnessite structure appears to us very plausible. The spectral contribution located at the highest binding energy was assigned to calcium phosphates containing $\mathrm{H}_{2} \mathrm{O}$ and/or $\mathrm{OH}^{-}$and its observation is in agreement with our findings for the $\mathrm{Ca} 2 \mathrm{p}$ line and the $\mathrm{Ca}$ L-edge spectra described above. Here, the formation of clusters like $\mathrm{CaH}\left(\mathrm{PO}_{4}\right)$ associated with water molecules is possible which are known from the minerals brushite $\left(\mathrm{CaH}\left(\mathrm{PO}_{4}\right) \cdot 2 \mathrm{H}_{2} \mathrm{O}\right)$ or octacalcium phosphate $\left(\mathrm{Ca}_{8} \mathrm{H}_{2}\left(\mathrm{PO}_{4}\right)_{6} \cdot 5 \mathrm{H}_{2} \mathrm{O}\right.$. Another possible reaction at $\mathrm{pH} 7$ is the formation of hydroxyapatite $\left(\mathrm{Ca}_{5}\left(\mathrm{PO}_{4}\right)_{3}(\mathrm{OH})\right)$. 


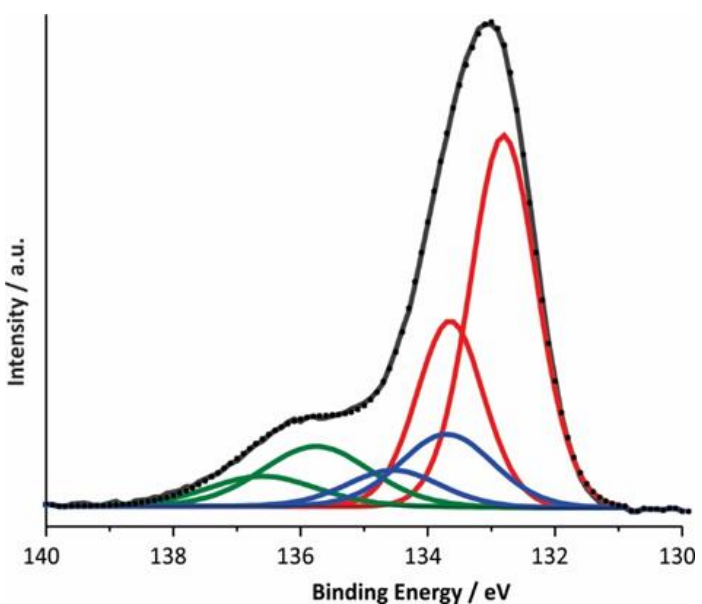

Figure 9. Deconvoluted P 2p XPS spectrum for a Ca-birnessite electrode after electrolysis under OER conditions $(16 \mathrm{~h}$ in $0.1 \mathrm{M}$ phosphate buffer at $\eta=540 \mathrm{mV}$ ).

The most obvious explanation for the appearance of the contributions of the $\mathrm{P} 2 \mathrm{p}$ line is the reaction of phosphate ions with the surface of the manganese oxide layer, where oxygen point-defects could react especially well with phosphate units. ${ }^{59}$ For this, different phosphate binding motifs are possible: direct binding of phosphate to the $\left[\mathrm{MnO}_{6}\right]_{\mathrm{n}}$-layer could occur via a single oxygen vacancy or a phosphate bonded via two oxygen atoms to two neighboring $\mathrm{O}$-defects. Another possibility is the reaction of phosphate with calcium ions located between the $\left[\mathrm{MnO}_{6}\right]$-layers, which are separated by a rather large $7 \AA$ interlayer space for birnessites. This is supported by the reduced $\mathrm{Ca}^{2+}$ concentration in phosphate enriched areas.

In conclusion, the XPS results can be interpreted by equilibria involving dynamic exchanges of $\mathrm{Ca}^{2+}, \mathrm{K}^{+}, \mathrm{PO}_{4}{ }^{3-}$ and $\mathrm{HPO}_{4}{ }^{2-}$ ions bound to the surfaces, within the pores and probably even between the $\left[\mathrm{MnO}_{6}\right]_{\mathrm{n}}$ layers of the birnessite material (see graphical abstract). Among the anions, phosphate species seem to have an especially high affinity for birnessites, leading to a substantial incorporation of phosphate into the birnessites' surface layers where catalytic water oxidation most likely occurs. The combination of XPS, NEXAFS and theoretical approaches indicates that the binding of phosphate can either occur directly via $\mathrm{O}$-vacancies in the $\left[\mathrm{MnO}_{6}\right]$ layers or also by the formation of $\left[\mathrm{Ca} / \mathrm{PO}_{4} / \mathrm{H}_{2} \mathrm{O}\right]$ - complexes within the layers. The latter appear to be of significant importance because close calcium-manganese and calcium-phosphate interactions are indicated by the detailed analyses not only of the $\mathrm{P} 2 \mathrm{p}$ but also the $\mathrm{Ca} 2 \mathrm{p}$ and $\mathrm{Ca}, \mathrm{Mn}$ L-edges signals. Finally, we would like to add that the described incorporation of phosphate is to a large extend reversible: if an anode "loaded" with phosphate by OER electrocatalysis is placed in deionised water for $12 \mathrm{~h}$, no XPS peaks for $\mathrm{P}$ can be detected any more.

\section{Conclusion}

While few studies on water-oxidation catalysis by manganese oxides emphasize the critical role of the electrolyte for effective water oxidation catalysis, our results clearly show the potential benefits of a rational, concerted development of catalyst and electrolyte in parallel. For Ca-birnessite, we find that the use of buffering electrolytes is generally beneficial and that phosphate-based systems seem to be particularly advantageous for the operation of birnessite-anodes at near-neutral conditions.

Our detailed investigation of the interactions between the Ca-birnessite material and (hydrogen) phosphate electrolytes during electrocatalysis provided proof for very dynamic, complicated ion exchange equilibria between the solution and the heterogeneous water-oxidation catalyst. Using a broad set of investigation methods (electron microscopy, EDX, XPS and NEXAFS), we could show that the elements carbon and calcium, which are part of the catalyst layer as a result of the preparation method, are fully $(\mathrm{C})$ or to a large degree $(\mathrm{Ca})$ eliminated from the material after some hours of operation as OER electrocatalyst. Further analysis of the XPS and NEXAFS spectra acquired after OER reveals that a large fraction of the remaining calcium-oxygen interactions is likely of covalent nature, preventing the complete dissolution of calcium from the material. It seems that phosphate plays a role in accruing this phenomenon as no hybridization was observed in the case of the imidazolium sulfate electrolyte, and much more $\mathrm{Ca}^{2+}$ ions left the structure. This in turn leads to a destabilization of the $\mathrm{Mn}^{3+}$ state resulting in a decrease of OER activity.

For the neutral potassium phosphate electrolyte, our data suggests that both $\mathrm{K}^{+}$and $\mathrm{H}_{\mathrm{n}} \mathrm{PO}_{4}{ }^{(3-\mathrm{n})-}$, enter the mesoporous birnessite layer. After some time, these ions can be found in the entire volume of the catalyst, with especially high concentrations at the top of the catalyst layer (where a new, probably re-precipitated material is formed) and on the inner surfaces of the pores.

The interpretation of XPS and NEXAFS data for a nanocrystalline, partially disordered manganese oxide like birnessite is complex and far from routine. However, our analysis is in agreement with previous investigations which indicated that the redox equilibrium $\mathrm{Mn}^{3+} \leftrightarrows \mathrm{Mn}^{4+}$ is of central importance for OER catalysis by birnessites. A significant concentration of $\mathrm{Mn}^{3+}$ ions at the surface of the oxide might be key for the material to be catalytically active. Mediated by bridging oxygen atoms, Mn cations interact with both calcium (which seems to influence its oxidation state) and phosphorous during electrocatalysis and furthermore $\mathrm{Ca}^{2+}$ and $\mathrm{H}_{\mathrm{n}} \mathrm{PO}_{4}{ }^{(3-\mathrm{n})}$ - additionally seem to form some kind of aggregates within the material as detected by XPS.

Overall, the operation of Ca-birnessite as water-oxidation catalyst in phosphate electrolytes significantly alters the manganese oxide material. Especially striking is the incorporation of (hydrogen)phosphate anions into the catalyst, where they stabilize $\mathrm{Ca}^{2+}$ in the structure and might additionally act as "internal bases" to shuttle protons released from the OER reaction at catalytic sites into the bulk of the solution. These special effects of the interaction of $\mathrm{H}_{\mathrm{n}} \mathrm{PO}_{4}{ }^{(3-\mathrm{n})-}$ with the catalyst might explain the markedly better OER-performance of the Ca-birnessites catalyst material in phosphate solutions in comparison to other buffering electrolytes. We would like to add that the processes described here might be closely related to the incorporation of phosphate ions into the much-studied "CoP,"-catalyst films generated by the electrodeposition of cobalt from phosphate-containing solutions. ${ }^{60}$ Thus amorphous $\mathrm{CoO}_{\mathrm{x}^{-}}$ and nanocrystalline, layered $\mathrm{MnO}_{\mathrm{x}}$ - electrocatalysts for water-oxidation show an important similarity: in addition to the atomic structure and morphology of the catalyst material, the interaction of the oxides with the ionic components of the electrolyte is of central importance for the catalytic process.

\section{ASSOCIATED CONTENT}

Supporting Information. Additional TEM analysis and spectroscopic information can be found in the supplemental information. This material is available free of charge via the Internet.

\section{AUTHOR INFORMATION}

\section{Corresponding Authors}

*E-mail: skorupska@fhi-berlin.mpg.de

*E-mail: cjooss@gwdg.de

*E-mail: philipp.kurz@ac.uni-freiburg.de

\section{Author Contributions}

The manuscript was written through contributions of all authors. 


\section{ACKNOWLEDGMENT}

This project was made possible by the generous financial support by the Federal Ministry of Education and Research (BMBF cluster project MANGAN), the German Research Foundation (DFG) priority program SPP1613, grants KU2885/2-2 and JO348/11-1 and SFB 1073, project C02, funded by DFG. T. E. J. acknowledges the Alexander-von-Humboldt Foundation for financial support.

\section{REFERENCES}

(1) Lewis, N. S.; Nocera, D. G. Powering the Planet: Chemical Challenges in Solar Energy Utilization. Proceedings of the National Academy of Sciences of the United States of America. October 24, 2006, pp 15729-15735.

(2) Katsounaros, I.; Cherevko, S.; Zeradjanin, A. R.; Mayrhofer, K. J. J. Oxygen Electrochemistry as a Cornerstone for Sustainable Energy Conversion. Angew. Chemie Int. Ed. 2014, 53 (1), 102121.

(3) Robinson, D. M.; Go, Y. B.; Mui, M.; Gardner, G.; Zhang, Z.; Mastrogiovanni, D.; Garfunkel, E.; Li, J.; Greenblatt, M.; Dismukes, G. C. Photochemical Water Oxidation by Crystalline Polymorphs of Manganese Oxides: Structural Requirements for Catalysis. J. Am. Chem. Soc. 2013, 135 (9), 3494-3501.

(4) Jiao, F.; Frei, H. Nanostructured Cobalt and Manganese Oxide Clusters as Efficient Water Oxidation Catalysts. Energy Environ. Sci. 2010, 3 (8), 1018.

(5) Menezes, P. W.; Indra, A.; Littlewood, P.; Schwarze, M.; Göbel, C.; Schomäcker, R.; Driess, M. Nanostructured Manganese Oxides as Highly Active Water Oxidation Catalysts: A Boost from Manganese Precursor Chemistry. ChemSusChem 2014, 7 (8), 2202-2211.

(6) Ramírez, A.; Hillebrand, P.; Stellmach, D.; May, M. M.; Bogdanoff, P.; Fiechter, S. Evaluation of $\mathrm{MnO}_{\mathrm{x}}, \mathrm{Mn}_{2} \mathrm{O}_{3}$, and $\mathrm{Mn}_{3} \mathrm{O}_{4}$ Electrodeposited Films for the Oxygen Evolution Reaction of Water. J. Phys. Chem. C 2014, 118 (26), 14073 14081.

(7) Smith, P. F.; Deibert, B. J.; Kaushik, S.; Gardner, G.; Hwang, S.; Wang, H.; Al-Sharab, J. F.; Garfunkel, E.; Fabris, L.; Li, J.; Dismukes, G. C. Coordination Geometry and Oxidation State Requirements of Corner-Sharing $\mathrm{MnO}_{6}$ Octahedra for Water Oxidation Catalysis: An Investigation of Manganite $(\gamma-\mathrm{MnOOH})$. ACS Catal. 2016, 6 (3), 2089-2099.

(8) Raabe, S.; Mierwaldt, D.; Ciston, J.; Uijttewaal, M.; Stein, H.; Hoffmann, J.; Zhu, Y.; Blöchl, P.; Jooss, C. In Situ Electrochemical Electron Microscopy Study of Oxygen Evolution Activity of Doped Manganite Perovskites. Adv. Funct. Mater. 2012, 22 (16), 3378-3388.

(9) Scholz, J.; Risch, M.; Stoerzinger, K. A.; Wartner, G.; ShaoHorn, Y.; Jooss, C. Rotating Ring-Disk Electrode Study of Oxygen Evolution at a Perovskite Surface: Correlating Activity to Manganese Concentration. J. Phys. Chem. C 2016, 120 (49), 27746-27756.

(10) Scholz, J.; Risch, M.; Wartner, G.; Luderer, C.; Roddatis, V.; Jooss, C. Tailoring the Oxygen Evolution Activity and Stability Using Defect Chemistry. Catalysts 2017, 7 (5), 139.

(11) Melder, J.; Bogdanoff, P.; Zaharieva, I.; Fiechter, S.; Dau, H.; Kurz, P. Water-Oxidation Electrocatalysis by Manganese Oxides: Syntheses, Electrode Preparations, Electrolytes and Two Fundamental Questions. Zeitschrift für Phys. Chemie 2020, 234 (5), 925-978.

(12) Mattioli, G.; Zaharieva, I.; Dau, H.; Guidoni, L. Atomistic Texture of Amorphous Manganese Oxides for Electrochemical Water Splitting Revealed by Ab Initio Calculations Combined with X-Ray Spectroscopy. J. Am. Chem. Soc. 2015, 137 (32), 10254-10267.

(13) Wiechen, M.; Zaharieva, I.; Dau, H.; Kurz, P. Layered Manganese Oxide for Water-Oxidation: Alkaline Earth Cations Influence Catalytic Activity in a Photosystem II-like Fashion. Chem. Sci. 2012, 3 (7), 2330-2339.

(14) Zaharieva, I.; González-Flores, D.; Asfari, B.; Pasquini, C.; Mohammadi, M. R.; Klingan, K.; Zizak, I.; Loos, S.; Chernev, P.; Dau, H. Water Oxidation Catalysis - Role of Redox and
Structural Dynamics in Biological Photosynthesis and Inorganic Manganese Oxides. Energy Environ. Sci. 2016, 9 (7), 2433-2443. Zaharieva, I.; Chernev, P.; Risch, M.; Klingan, K.; Kohlhoff, M.; Fischer, A.; Dau, H. Electrosynthesis, Functional, and Structural Characterization of a Water-Oxidizing Manganese Oxide. Energy Environ. Sci. 2012, 5 (5), 7081-7089.

(16) Zaharieva, I.; Najafpour, M. M.; Wiechen, M.; Haumann, M.; Kurz, P.; Dau, H. Synthetic Manganese Calcium Oxides Mimic the Water-Oxidizing Complex of Photosynthesis Functionally and Structurally. Energy Environ. Sci. 2011, 4, 2400-2408. Shevchenko, D.; Anderlund, M. F.; Styring, S.; Dau, H.; Zaharieva, I.; Thapper, A. Water Oxidation by Manganese Oxides Formed from Tetranuclear Precursor Complexes: The Influence of Phosphate on Structure and Activity. Phys. Chem. Chem. Phys. 2014, 16 (24), 11965-11975.

(18) González-Flores, D.; Zaharieva, I.; Heidkamp, J.; Chernev, P.; Martínez-Moreno, E.; Pasquini, C.; Mohammadi, M. R.; Klingan, K.; Gernet, U.; Fischer, A.; Dau, H. Electrosynthesis of Biomimetic Manganese-Calcium Oxides for Water Oxidation Catalysis-Atomic Structure and Functionality. ChemSusChem 2016, 9 (4), 379-387.

(19) Jiao, F.; Frei, H. Nanostructured Manganese Oxide Clusters Supported on Mesoporous Silica as Efficient Oxygen-Evolving Catalysts. Chem. Commun. 2010, 46 (17), 2920.

(20) Indra, A.; Menezes, P. W.; Zaharieva, I.; Baktash, E.; Pfrommer, J.; Schwarze, M.; Dau, H.; Driess, M. Active Mixed-Valent $\mathrm{MnO}_{x}$ Water Oxidation Catalysts through Partial Oxidation (Corrosion) of Nanostructured MnO Particles. Angew. Chemie Int. Ed. 2013 , $52(50), 13206-13210$.

(21) Fekete, M.; Hocking, R. K.; Chang, S. L. Y.; Italiano, C.; Patti, A. F.; Arena, F.; Spiccia, L. Highly Active Screen-Printed Electrocatalysts for Water Oxidation Based on $\beta$-Manganese Oxide. Energy Environ. Sci. 2013, 6 (7), 2222-2232.

(22) Najafpour, M. M.; Moghaddam, A. N.; Dau, H.; Zaharieva, I. Fragments of Layered Manganese Oxide Are the Real Water Oxidation Catalyst after Transformation of Molecular Precursor on Clay. J. Am. Chem. Soc. 2014, 136 (20), 7245-7248.

(23) Frey, C. E.; Kurz, P. Water Oxidation Catalysis by Synthetic Manganese Oxides with Different Structural Motifs: A Comparative Study. Chem. Eur. J. 2015, 21 (42), 14958-14968.

(24) Najafpour, M. M.; Ebrahimi, F.; Abasi, M.; Hosseini, S. M. Manganese Oxides Supported on Nano-Sized Metal Oxides as Water-Oxidizing Catalysts for Water Splitting Systems: 2-WaterOxidizing Activities. Int. J. Hydrogen Energy 2016, 41 (41), 18472-18477.

(25) Golden, D. C.; Dixon, J. B.; Chen, C. C. Ion Exchange, Thermal Transformations, and Oxidizing Properties of Birnessite. Clays Clay Miner. 1986, 34 (5), 511-520.

(26) Johnson, E. A.; Post, J. E. Water in the Interlayer Region of Birnessite: Importance in Cation Exchange and Structural Stability. Am. Mineral. 2006, 91 (4), 609-618.

(27) Frey, C. E.; Wiechen, M.; Kurz, P. Water-Oxidation Catalysis by Synthetic Manganese Oxide-Systematic Variations of the Calcium Birnessite Therme. Dalt. Trans. 2014, 43 (11), 4370 4379 .

(28) Lee, S. Y.; González-Flores, D.; Ohms, J.; Trost, T.; Dau, H.; Zaharieva, I.; Kurz, P. Screen-Printed Calcium-Birnessite Electrodes for Water-Oxidation at Neutral $\mathrm{PH}$ and an "Electrochemical Harriman Series." ChemSusChem 2014, 7, 3442-3451.

(29) Risch, M.; Klingan, K.; Ringleb, F.; Chernev, P.; Zaharieva, I.; Fischer, A.; Dau, H. Water Oxidation by Electrodeposited Cobalt Oxides-Role of Anions and Redox-Inert Cations in Structure and Function of the Amorphous Catalyst. ChemSusChem 2012, 5 (3), 542-549.

(30) Klingan, K.; Ringleb, F.; Zaharieva, I.; Heidkamp, J.; Chernev, P.; Gonzalez-Flores, D.; Risch, M.; Fischer, A.; Dau, H. Water Oxidation by Amorphous Cobalt-Based Oxides: Volume Activity and Proton Transfer to Electrolyte Bases. ChemSusChem 2014, 7 (5), 1301-1310.

(31) Risch, M.; Ringleb, F.; Kohlhoff, M.; Bogdanoff, P.; Chernev, P.; Zaharieva, I.; Dau, H. Water Oxidation by Amorphous CobaltBased Oxides: In Situ Tracking of Redox Transitions and Mode of Catalysis. Energy Environ. Sci. 2015, 8 (2), 661-674.

(32) Seitz, L. C.; Hersbach, T. J. P.; Nordlund, D.; Jaramillo, T. F. 
Enhancement Effect of Noble Metals on Manganese Oxide for the Oxygen Evolution Reaction. J. Phys. Chem. Lett. 2015, 6 (20), 4178-4183.

Najafpour, M. M.; Renger, G.; Hołyńska, M.; Moghaddam, A. N.; Aro, E.-M.; Carpentier, R.; Nishihara, H.; Eaton-Rye, J. J.; Shen, J.-R.; Allakhverdiev, S. I. Manganese Compounds as Water-Oxidizing Catalysts: From the Natural Water-Oxidizing Complex to Nanosized Manganese Oxide Structures. Chem. Rev. 2016, 116 (5), 2886-2936.

Izgorodin, A.; Winther-Jensen, O.; MacFarlane, D. R. On the Stability of Water Oxidation Catalysts: Challenges and Prospects. Aust. J. Chem. 2012, 65 (6), 638-642.

(35) Najafpour, M. M.; Sedigh, D. J.; Pashaei, B.; Nayeri, S. Water Oxidation by Nano-Layered Manganese Oxides in the Presence of Cerium (IV) Ammonium Nitrate: Important Factors and a Proposed Self-Repair Mechanism. New J. Chem. 2013, 37 (8), 2448-2459.

(36) Najafpour, M. M.; Sedigh, D. J. Water Oxidation by Manganese Oxides, a New Step towards a Complete Picture: Simplicity Is the Ultimate Sophistication. Dalt. Trans. 2013, 42 (34), 1217312178.

(37) Kanady, J. S.; Tsui, E. Y.; Day, M. W.; Agapie, T. A Synthetic Model of the $\mathrm{Mn}_{3} \mathrm{Ca}$ Subsite of the Oxygen-Evolving Complex in Photosystem II. Science (80-. ). 2011, 333 (6043), 733-736.

(38) Knop-Gericke, A.; Kleimenov, E.; Hävecker, M.; Blume, R.; Teschner, D.; Zafeiratos, S.; Schlögl, R.; Bukhtiyarov, V. I.; Kaichev, V. V; Prosvirin, I. P.; Nizovskii, A. I.; Bluhm, H.; Barinov, A.; Dudin, P.; Kiskinova, M. Chapter 4 X-Ray Photoelectron Spectroscopy for Investigation of Heterogeneous Catalytic Processes. In Advances in Catalysis; Elsevier, 2009; pp 213-272.

(39) Tanuma, S.; Powell, C. J.; Penn, D. R. Calculations of Electron Inelastic Mean Free Paths (IMFPS). IV. Evaluation of Calculated IMFPs and of the Predictive IMFP Formula TPP-2 for Electron Energies between 50 and 2000 EV. Surf. Interface Anal. 1993, 20 (1), 77-89.

(40) van Schooneveld, M. M.; DeBeer, S. A Close Look at Dose: Toward L-Edge XAS Spectral Uniformity, Dose Quantification and Prediction of Metal Ion Photoreduction. J. Electron Spectros. Relat. Phenomena 2015, 198, 31-56.

(41) Gilbert, B.; Frazer, B. H.; Belz, A.; Conrad, P. G.; Nealson, K H.; Haskel, D.; Lang, J. C.; Srajer, G.; De Stasio, G. Multiple Scattering Calculations of Bonding and X-Ray Absorption Spectroscopy of Manganese Oxides. J. Phys. Chem. A 2003, 107 (16), 2839-2847.

(42) Qiao, R.; Chin, T.; Harris, S. J.; Yan, S.; Yang, W. Spectroscopic Fingerprints of Valence and Spin States in Manganese Oxides and Fluorides. Curr. Appl. Phys. 2013, 13 (3), 544-548.

(43) Voss, S.; Fonin, M.; Rüdiger, U.; Burgert, M.; Groth, U.; Dedkov, Y. S. Electronic Structure of $\mathrm{Mn}_{12}$ Derivatives on the Clean and Functionalized Au Surface. Phys. Rev. B - Condens. Matter Mater. Phys. 2007, 75 (4), 045102.

(44) Khan, M.; Suljoti, E.; Singh, A.; Bonke, S. A.; Brandenburg, T.; Atak, K.; Golnak, R.; Spiccia, L.; Aziz, E. F. Electronic Structural Insights into Efficient $\mathrm{MnO}_{\mathrm{x}}$ Catalysts. J. Mater. Chem. A 2014, 2 (43), 18199-18203.

(45) Morgan, W. E.; Van Wazer, J. R.; Stec, W. J. Inner-Orbital Photoelectron Spectroscopy of the Alkali Metal Halides, Perchlorates, Phosphates, and Pyrophosphates. J. Am. Chem. Soc. 1973, 95 (3), 751-755.
(46) Lo, P.-H. The Electrochemical Behavior of Electroless Plated Ni$\mathrm{P}$ Alloys in Concentrated $\mathrm{NaOH}$ Solution. J. Electrochem. Soc. 1995, 142 (1), 91.

(47) Fernández-Rodríguez, J.; Toby, B.; Van Veenendaal, M. Xclaim: A Graphical Interface for the Calculation of Core-Hole Spectroscopies. J. Electron Spectros. Relat. Phenomena $\mathbf{2 0 1 5}$, 202, 81-88.

(48) F. Sulzmann; Jang, W.; Melder, J.; Rohner, C.; Girgsdies, F.; Knop-Gerickec, A.; Schlögl, R.; T.Jones; Kurz, P.; Skorupska, K. No Title. Manuscr. to be Submitt.

(49) Tesch, M. F.; Bonke, S. A.; Jones, T. E.; Shaker, M. N.; Xiao, J.; Skorupska, K.; Mom, R.; Melder, J.; Kurz, P.; Knop-Gericke, A.; Schlögl, R.; Hocking, R. K.; Simonov, A. N. Evolution of Oxygen-Metal Electron Transfer and Metal Electronic States During Manganese Oxide Catalyzed Water Oxidation Revealed with In Situ Soft X-Ray Spectroscopy. Angew. Chemie 2019, 131 (11), 3464-3470.

(50) de Boer, D. K. G.; Haas, C.; Sawatzky, G. A. Exciton Satellites in Photoelectron Spectra. Phys. Rev. B 1984, 29 (8), 4401-4419.

(51) Kumar, S.; Raju, V. S.; Bera, S.; Vijaynandhini, K.; Kutty, T. R N. Studies on Surface Composition and Chemical States of Calcium Manganites. Nucl. Instruments Methods Phys. Res. Sect B Beam Interact. with Mater. Atoms 2005, 237 (3-4), 623-630.

(52) Bocquet, A. E.; Mizokawa, T.; Morikawa, K.; Fujimori, A.; Barman, S. R.; Maiti, K.; Sarma, D. D.; Tokura, Y.; Onoda, M. Electronic Structure of Early 3d-Transition-Metal Oxides by Analysis of the 2pcore-Level Photoemission Spectra. Phys. Rev. B 1996, 53 (3), 1161-1170.

(53) van der Laan, G.; Westra, C.; Haas, C.; Sawatzky, G. A. Satellite Structure in Photoelectron and Auger Spectra of Copper Dihalides. Phys. Rev. B 1981, 23 (9), 4369-4380.

(54) Pinaud, B. A.; Chen, Z.; Abram, D. N.; Jaramillo, T. F. Thin Films of Sodium Birnessite-Type $\mathrm{MnO}_{2}$ : Optical Properties, Electronic Band Structure, and Solar Photoelectrochemistry. J. Phys. Chem. C 2011, 115 (23), 11830-11838.

(55) Lucht, K. P.; Mendoza-Cortes, J. L. Birnessite: A Layered Manganese Oxide To Capture Sunlight for Water-Splitting Catalysis. J. Phys. Chem. C 2015, 119 (40), 22838-22846.

(56) Mansfield, M. W. D. The Ca I Absorption Spectrum in the Extreme Ultraviolet: Excitation of the 2p Subshell. Proc. R. Soc. A Math. Phys. Eng. Sci. 1976, 348 (1652), 143-151.

(57) Himpsel, F. J.; Karlsson, U. O.; McLean, A. B.; Terminello, L. J.; De Groot, F. M. F.; Abbate, M.; Fuggle, J. C.; Yarmoff, J. A.; Thole, B. T.; Sawatzky, G. A. Fine Structure of the Ca 2p X-RayAbsorption Edge for Bulk Compounds, Surfaces, and Interfaces. Phys. Rev. B 1991, 43 (9), 6899-6907.

(58) Landis, W. J.; Martin, J. R. X-ray Photoelectron Spectroscopy Applied to Gold-decorated Mineral Standards of Biological Interest. J. Vac. Sci. Technol. A 1984, 2 (2), 1108-1111.

(59) Sharma, C. V. K.; Chusuei, C. C.; Clérac, R.; Möller, T.; Dunbar, K. R.; Clearfield, A.; Sharma, C. V. K.; Chusuei, C. C.; Clérac, R.; Möller, T.; Dunbar, K. R.; Clearfield, A. Magnetic Property Studies of Manganese-Phosphate Complexes. Inorg. Chem. 2003, 42 (25), 8300-8308.

(60) Lutterman, D. A.; Surendranath, Y.; Nocera, D. G. A SelfHealing Oxygen-Evolving Catalyst. J. Am. Chem. Soc. 2009, 131 (11), 3838-3839. 


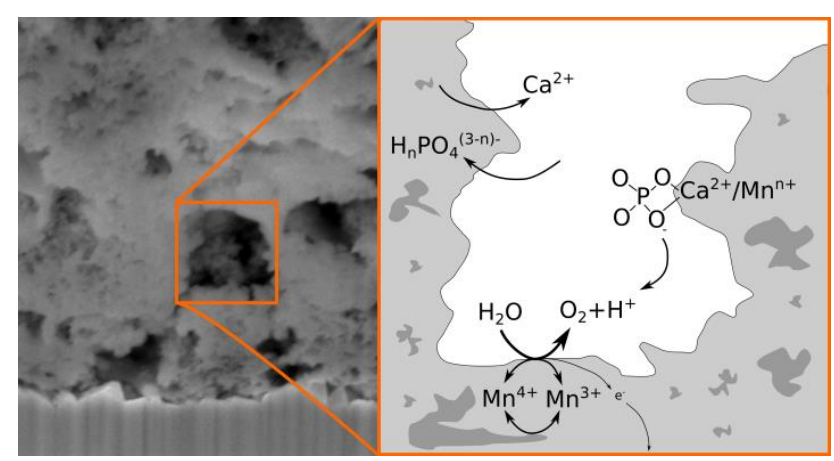

